\title{
Evolución cronológica del arancel y de las políticas aracelarias en el Perú
}

Marco Antonio Huamán Sialer*

* Vocal Presidente de la Sala de Aduanas del Tribunal Fiscal (Sala 6), profesor de la Pontificia Universidad Católica del Perú, Universidad Nacional Mayor de San Marcos, ESAN, Universidad de Lima y Universidad Alas Peruanas.

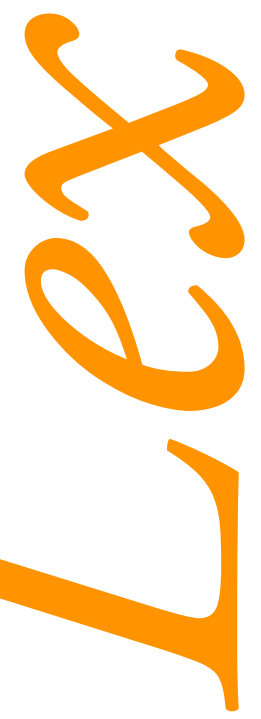





\section{Introducción}

Pocas son las fuentes bibliográficas e históricas referentes a un estudio profundo y detallado de la evolución cronológica de los aranceles y las políticas arancelarias en el Perú que tenemos en nuestro país. Ello es muy importante y necesario en razón de que conociendo nuestro pasado podemos mejorar nuestro futuro.

El común denominador de las economías en el mundo ha sido alcanzar un nivel óptimo de vida para los habitantes. La evolución del arancel ha correspondido a la necesidad de desarrollar el comercio exterior como instrumento para lograr ese ansiado nivel de vida. En la medida en que han ido aumentando las carencias de la población, los gobiernos han tomado conciencia de la importancia de la actividad comercial en pos del crecimiento económico de sus países.

En el Perú, desde la época colonial hasta nuestros días, el arancel ha cumplido (entre otros roles) un fin recaudatorio. Precisamente, el origen del arancel en el Perú coincidió con la necesidad de solventar los gastos públicos, por lo que asumió una función fiscalista. Sin embargo, con la evolución de la industria y del comercio, el arancel comenzó a ser utilizado como mecanismo de política comercial cumpliendo además un rol proteccionista o de instrumento de regulación del comercio exterior.

El arancel puede ser entendido como impuesto, es decir, como el documento emitido por la autoridad correspondiente que fija las tasas arancelarias de acuerdo a una política arancelaria establecida o como instrumento de política comercial.

El presente artículo analiza la evolución del arancel como instrumento de política comercial y el desarrollo de las políticas arancelarias aplicadas en el Perú desde la época colonial y el Virreynato hasta la fecha. Se hace una ligera mención a la época incaica. 


\section{2. Época Incaica}

Durante la época incaica existió el "cobro del portazgo" para atravesar los puentes. Sobre ello, Juan Adriazola cita testimonios coincidentes y contemporáneos a la conquista de Francisco Pizarro. Sostiene que Pedro Cieza de León menciona un puente donde, en tiempo de los incas, solía haber portalgueros que cobraban tributos a los que pasaban.

Asimismo, el referido autor, citando a Francisco de Xerex, reproduce una cita textual de éste último en su obra Verdadera relación de la conquista del Perú (1534) en los siguientes términos:

Está una casa al principio de un puente donde reside un guarda que recibe el portazgo de los que van y vienen y pagándolo en la misma cosa que llevan y ninguno puede sacar carga del pueblo sino la mete (...). Ningún pasajero puede entrar ni salir por otro camino con carga sino por donde está la guarda so pena de muerte. ${ }^{1}$

En relación a lo expresado, puedo decir que existió un atisbo inicial de cobró y de control al ingresar las mercancías a las ciudades del imperio.

\section{La Colonia}

Durante el Virreynato se estableció una política proteccionista. El cobro de los derechos de aduana, denominado en esa época almojarifazgo ${ }^{2}$, fue utilizado para cumplir con la Real Cédula debido a que existía la obligación de las colonias de enviar todo el producto del cobro a España.

El Almojarifazgo era el impuesto que se pagaba por introducir y sacar bienes por los puertos. Aunque su alícuota fue variable durante toda la Colonia, esta alcanzó para la importación un promedio de 5\% del valor de los bienes en el lugar de destino. ${ }^{3}$ La evaluación se hacía sobre el valor de la mercancía a los 30 días posteriores a la llegada a tierra firme. Para el caso de las exportaciones, alcanzó un promedio de $2,5 \%$ del valor de las mercancías.

En un inicio, el cobro del Almojarifazgo estuvo a cargo de los Oficiales de las Cajas Reales, pasando luego a cargo del Tribunal del Consulado en 1640, siendo finalmente encomendado a la Aduana en 1773 con la expedición del Reglamento de Comercio y Organización de Aduanas.

ADRIAZOLA ZEVALLOS, Juan Carlos. Derecho Aduanero Tributario. p.22

Los árabes fueron quienes impulsaron el derecho de aduana (almojarifazgo). Se le denominó así porque el encargado de la recaudación de este impuesto era el almojarife.

3 El monto a pagar por concepto de almojarifazgo era fijado en relación con el valor de las mercancías en el lugar de destino y no por el precio que tuvieran éstas en el puerto de embarque. 
El reglamento citado fue aprobado por Real Decreto de 02 de octubre de 1773, promulgado por el entonces Virrey don Manuel Amat y Juniet, y estableció algunas exoneraciones o aumentos del arancel, dependiendo del tipo de producto y de su procedencia (si eran procedentes de España o no).

El Real Decreto dispuso además la creación de la primera Oficina de Aduanas, con el objeto de que se administren eficazmente los ingresos y egresos en los que se incurría por el cobro del almojarifazgo y demás impuestos.

Tal como señalan Aliaga Ortiz y Chirinos Lévano, la Aduana de Lima fue considerada la Real Administración de almojarifazgo y alcabala ${ }^{4}$ y tuvo su jurisdicción en todo el territorio del Virreynato, excepto las provincias de Tucumán, Paraguay, Río de la Plata y Chile. Posteriormente, se crearon las Administraciones Provinciales, y en España se estableció la Casa de Contratación de Sevilla que tuvo como función controlar el comercio de España con sus Colonias, así se tratasen de personas, animales o mercancías. ${ }^{5}$

En relación al Real Decreto, se desarrollaron aspectos referidos al personal de la Oficina de Aduanas, sus haberes, organización, disposiciones legales, Arancel de Aduanas de Importación (almojarifazgo de entrada) y de Exportación (almojarifazgo de salida).

El Perú gozó de una intensa actividad comercial hasta 1779, disminuyendo el flujo controlado debido a las incorrectas medidas adoptadas que, en lugar de fomentar el libre comercio, acentuó aún más el contrabando.

A fines del siglo XVIII importábamos más de lo que se exportaba por lo que la balanza comercial fue desfavorable.

En este contexto, quizá se pudo tomar como decisión el aumento de aranceles como medida de recaudación; sin embargo, se consideró conveniente más bien ampliar el ámbito de comercio con España.

\section{De 1821 a 1830}

A inicios de este periodo, el Perú atravesaba una crisis económica, consecuencia de la lucha por la Independencia, motivo por el cual se asumió una posición proteccionista, siendo

La alcabala gravaba todas las transacciones de bienes (excepto los instrumentos de culto, medicinas, pan, entre otros bienes), sin perjuicio del almojarifazgo. Se pagaba sobre la compra y venta y generalmente lo hacía el que vendía.

5 ALIAGA, Juanita y CHIRINOS, Celinda. Trabajo de Investigación para optar el Título de "Oficial de Aduanas", Tema:

"El Arancel de Aduanas". Lima: Escuela Nacional de Aduanas "III Curso de Oficiales de Aduanas", 1996, p. 24 
utilizado el arancel no solo como una fuente de ingresos fiscales, sino también como una herramienta para resguardar la agricultura y la industria manufacturera.

Durante 1821-1830 se expidieron tres reglamentos que establecieron derechos ad valorem y específicos (expresados en porcentajes y pesos, respectivamente) sobre el valor de la mercancía que se ajustaba según los valores del mercado local.

Los valores eran establecidos por una comisión de comerciantes y personal de aduanas, quienes determinaban la base (lista de precios para mercancías importadas) para el cálculo de los tributos. Esta se publicaba el primer día de cada mes en las plazas.

$\mathrm{Al}$ proclamarse la Independencia se expidió un Reglamento Provisional de Comercio que contenía un Arancel de Aduanas, además de disposiciones para agilizar el comercio y proteger la producción nacional. Este reglamento dio inicio a un atractivo movimiento marítimo en el país.

Los derechos de aduana a la importación fueron en aumento en cada reglamento, diferenciándose si la mercancía venía o no en barcos de bandera peruana, siendo recién en 1826 que el reglamento estableció un único derecho de importación de 30\% para naves de cualquier bandera.

El reglamento de 1826 adicionalmente amplió la exoneración a productos necesarios para el desarrollo de la agricultura, ciencias, medicinas, arte, cultura, actividad minera y otros, y fijó un arancel de $80 \%$ para los bienes que pudieran perjudicar a la agricultura e industria, como medida de protección.

Las restricciones (arancelarias y no arancelarias) fueron en aumento hasta que, a fines del periodo, se prohibió la importación de bienes que eran producidos también en el país.

A pesar de la política proteccionista del periodo 1821-1830, no existieron intentos de industrialización, pues los bienes manufacturados y exportados eran producidos por extranjeros, constituyendo el mayor porcentaje de nuestras exportaciones la materia prima. Los motivos subyacentes a la política proteccionista aplicada en esta etapa fueron principalmente el proceso de Independencia y la severa crisis económica ocasionada por dicho proceso, los cuales motivaron a que se recurra al arancel como fuente principal de ingresos fiscales para equilibrar las arruinadas finanzas.

El origen de los derechos arancelarios en nuestra historia coincide con la necesidad de financiar los gastos públicos, por ello ha cumplido una función recaudadora en el desarrollo de las políticas comerciales asumidas por el Perú. Sin embargo, el arancel no solo ha tenido un 
rol fiscalista, pues la evolución de la industria que surgió después de la Revolución Industrial trajo consigo la especialización de productos y producción a gran escala afectando los precios tradicionales. Es en ese contexto que el arancel se adoptó como instrumento de política comercial para proteger y promover las industrias nacionales, alentando su desarrollo y crecimiento de las exportaciones, lo cual será materia de análisis más adelante.

\section{De 1831 a 1870}

Durante este periodo se expidieron códigos comerciales de tendencia liberal (de 1833, $1836,1840,1852$ y 1864) debido a que se buscaba cambiar la tendencia proteccionista impuesta con los reglamentos del periodo anterior que acentuaron el contrabando y, por tanto, la disminución de los ingresos fiscales. Los derechos arancelarios fueron reducidos logrando convertirse en la principal fuente de ingresos hasta la década de 1840, cuando la exportación del guano comenzó a generar mayores ingresos. ${ }^{7}$

En la década de 1840, tuvimos una etapa de recuperación económica, no solo por el comercio del guano sino también por el crecimiento de los volúmenes de exportación e importación, puesto que entre 1840-1849 las exportaciones se incrementaron en un 113\% y las importaciones crecieron en un 87\% entre $1835-1839$ y $1845-1849$.

Este periodo de carácter liberal no varió sustancialmente con el arancel proteccionista de 1849 , promulgado por la presión ejercida por los artesanos ${ }^{8}$, quienes vieron perjudicados sus intereses con el incremento de las importaciones. Este arancel estableció un derecho específico de $90 \%$ del precio en el mercado local de la mercancía importada que competía o podía competir con productos nacionales.

La tendencia proteccionista impuesta con el arancel de 1849 tuvo una vigencia corta, ya que en 1852 y, posteriormente, en diciembre de 1864, se expidieron dos códigos comerciales de corriente liberal que establecieron arancel cero para artículos de uso industrial y derechos arancelarios ad valorem para las demás mercancías entre 3\% a 90\%, en el caso del Reglamento de Comercio de 1852, y el de 1864 entre 3\% a 30\%, sobre el valor determinado por la comisión integrada por los comerciantes y Vistas de Aduanas a la cual se le había incluido un empleado de la Hacienda. Asimismo, dichos códigos también incluyeron derechos específicos, en tanto que el de 1852 gravó con derechos específicos al tabaco, el de 1864 gravó al aceite de oliva, alimentos, bebidas, velas, jabón, etc.

A fines de la década de 1840, la economía peruana experimentó una mayor integración a la economía internacional debido al comercio del guano, lo que llevó a realizar mayores

7 Durante 1830-1885, los productos de exportación principales fueron la plata, guano y salitre.

8 En la década de 1840, el sector manufacturero estuvo constituido principalmente por artesanos. 
importaciones, a depender más de los ingresos fiscales generados por el guano y a liberalizar la economía, según sostiene Carlos Boloña.?

Durante las décadas de 1850 y 1860, la política arancelaria liberal en lugar de permitir el crecimiento de las importaciones y exportaciones de manera equilibrada con el impulso de la producción nacional, lo que logró fue perjudicar la producción artesanal y el cierre de la mayoría de las escasas fábricas existentes en esa época.

En cuanto a la participación de los ingresos fiscales, durante la década de 1840 los derechos de importación constituyeron la fuente principal; en cambio, desde la década de 1850 hasta la primera mitad de la década de 1870 el guano se convirtió en la principal fuente de ingresos al representar entre 34-68\% del total de ingresos, en segundo lugar los préstamos que representaron entre $14-25 \%$ y por último los ingresos aduaneros que se redujeron a una participación de 33 a $12 \%$.

\section{De 1870 a 1883}

El Código Comercial de 1864 de corte liberal estuvo vigente hasta 1870, década en la que el Perú optó por incrementar los aranceles como medida de recaudación por varios motivos, entre ellos, por la crisis económica ocasionada por la guerra con Chile, por la reducción del precio mundial de la plata y los pocos ingresos del guano.

La década de 1870 fue una década de crisis económica. Las ganancias provenientes de la exportación no fueron debidamente destinadas, invirtiéndose en la importación de productos suntuarios. Así, las prácticas liberales que permitieron una balanza comercial positiva no se plasmaron en la industrialización del país.

En diciembre de 1872 , se aprobó un nuevo arancel de tendencia recaudadora por la necesidad de ingresos fiscales. Este arancel elevó los derechos del arancel de 1864, gravó con $10 \%$ ad valorem todos los bienes hasta entonces liberados e impuso derechos específicos sobre los vinos y licores.

Entre 1881 a 1883, la política arancelaria fue establecida por los chilenos, ya que estaban en el poder durante la invasión al Perú, por lo que en 1881 se fijó una tasa ad valorem de $35 \%$ para todas las mercancías y $0 \%$ en caso de ser de procedencia chilena, las que posteriormente también fueron grabadas.

9 BOLOÑA BEHR, Carlos. Políticas Arancelarias en el Perú 1880-1980. Lima: Instituto de Economía de Libre Mercado, 1994, p. 52. 
Con el Tratado de Paz de Ancón (octubre de 1883) comenzó el retiro de los chilenos y también un nuevo periodo en la política arancelaria peruana.

\section{De 1883 a 1910}

Durante los años de 1883 a 1890, el Perú lidió con una economía deteriorada al haber sido derrotado en la guerra con Chile. Siendo los sectores agrario, minero y manufacturero considerablemente perjudicados, así como también las finanzas públicas, debido a que las fuentes de ingresos fiscales (guano y salitre) prácticamente habían desaparecido.

Entre 1884 a 1885, el volumen de las exportaciones alcanzó únicamente un 30\% del nivel alcanzado el 1877 , además ya no contábamos con el guano y el salitre que habían significado aproximadamente el $70 \%$ del volumen total de las exportaciones. En estos años, las importaciones también se vieron afectadas por la reducción de la entrada de moneda extranjera, lo cual se debió a la disminución del volumen de las exportaciones, al incumplimiento en el pago de la deuda externa, la caída de los precios de exportación y al deterioro de los términos de intercambio.

El gobierno necesitaba recurrir a otras fuentes de ingresos, motivo por el cual se decidió tomar como fuente de ingresos fiscales nuevamente al arancel, replanteándose la política arancelaria. Sin embargo, el arancel también cumplió con fines proteccionistas en el periodo de 1884-1910, debido que se buscó desarrollar los sectores agrario, minero y manufacturero.

En este contexto, se adoptaron ciertas medidas, en octubre de 1883 se dispuso aplicar el Arancel de 1872 y el Arancel de Aforos de 1881, con ciertas modificaciones, las cuales consistían en incrementar los derechos de importación en un 5\% para los muebles, medicinas y para los bienes hasta entonces liberados; un 10\% adicional para los textiles y ciertos productos y $15 \%$ más para los vinos y demás licores.

En abril de 1884, se modificó transitoriamente el arancel, elevándose a 25\% la tasa aplicable a los textiles hasta entonces gravados con 10\%; los producto de mercería y diversos productos gravados hasta esa fecha con $8 \%, 10 \%$ y $15 \%$ fueron gravados con 30\%; los productos anteriormente liberados fueron gravados con un arancel de 10\% (excepto carbón, mercurio, maquinaria y algunos insumos).

En noviembre de 1884, se aprobó un arancel permanente, el cual comenzó a regir en 1885 y estableció un incremento de niveles arancelarios; sin embargo, ello no significó un incremento importante de los ingresos fiscales, por lo que resultaba necesario efectuar nuevamente una reforma arancelaria en el país. 
En 1886, se aprobó un nuevo arancel (vigente a partir del 01 de enero de 1887) con niveles arancelarios inferiores, estipulando que resultaba necesario realizar reformas a fin de reducir el costo de vida, promover el comercio y la industria, entre otros objetivos; sin embargo, los ingresos aduaneros tampoco mejoraron.

En 1888, el ministro de Hacienda encargó a una comisión investigadora analizar la política arancelaria. La comisión recomendó un nivel arancelario de 40\% como el de 1886 pero con exoneraciones a ciertos insumos y bienes de capital (madera, hierro, acero, explosivos para minas, grasas y soda cáustica, entre otros), revelando de esta manera una tendencia proteccionista.

La reforma arancelaria de 1888 elevó el nivel de protección mediante la reducción de los derechos de importación de insumos y bienes de capital y el incremento de los derechos arancelarios aplicables a ciertos bienes finales. En ese contexto, se aprobó el Arancel de 1888, el cual no modificó en gran parte el Arancel de 1886, aunque se introdujeron ciertos cambios importantes debido a las recomendaciones proteccionistas de la comisión investigadora, tales como: exoneraciones para los insumos y bienes de capital, incremento de los derechos específicos aplicables al trigo y arroz, y reducción de los derechos de importación a las joyas y metales preciosos, entre otros.

La promulgación de los Aranceles de 1886 y 1888 se debió a la necesidad de recaudar en la etapa posterior a la Guerra del Pacífico y fueron el resultado de los cambios en el rumbo de la política arancelaria de la década de 1880, pues a inicios de este periodo se buscó incrementar los ingresos fiscales con aranceles altos, pero que gradualmente se fueron orientando al proteccionismo al incrementar los derechos arancelarios de los bienes finales y reducir los de los insumos y bienes de capital, contribuyendo de esta manera a fomentar las actividades manufactureras.

La década de 1890 significó para el Perú una recuperación económica de los sectores productivos. El sector exportador agrícola se desarrolló, los sectores minero y manufacturero crecieron en forma complementaria, así también los sectores financiero y comercial. ${ }^{10}$

La controversia entre los defensores del proteccionismo y del libre comercio llegó a su punto máximo a fines del siglo XIX. Los partidarios del libre comercio consideraban que una política proteccionista era insuficiente, pues lo que se había logrado hasta esos años era la pérdida de ingresos fiscales que, entre 1898-1902, representó el 5\% de los derechos de

10 En 1887, se creó la Cámara de Comercio del Callao y en 1888 la Cámara de Comercio de Lima, ambas cámaras fueron creadas con el objeto de representar los intereses comerciales nacionales y extranjeros en materia de impuestos, derechos de importación, así como en otras materias. 
importación recaudados en 1902; fomento del contrabando; reducción de la riqueza del país debido al costo elevado del producto nacional e incremento del costo de vida; y que por tanto el libre comercio era el sistema que contribuía al bienestar de la clase trabajadora. Este grupo resultó vencedor porque a inicios de la década de 1900, como veremos, se dio inicio a una tendencia liberal.

En diciembre de 1900, se aprobó un nuevo Arancel de Aforos en el que participaron la Cámara de Comercio de Lima y la Sociedad Nacional de Industrias, aunque esta última no obtuvo la victoria con respecto a la protección arancelaria, ya que pudo más la influencia de la Cámara de Comercio.

Durante 1900 a 1910, continuó la recuperación económica pero a tasas de crecimiento inferiores, debido a las crisis comerciales de 1902-1904 (precio internacional del azúcar cayó en 50\%) y de 1907-1908 (como consecuencia de una sequía).

El gobierno consideró que el nuevo arancel debía basarse en derechos específicos en vez de derechos ad valorem y en 1910 entró en vigencia el primer arancel (Ley No 1320 del 16 de noviembre de 1910) basado únicamente en derechos específicos, cuyas tasas eran equivalentes al arancel ad valorem sustituido. Para Boloña, durante la década de 1900-1910 se contuvo la tendencia proteccionista, dejando listo el camino hacia medidas más liberales ${ }^{11}$.

De acuerdo a lo expuesto, el arancel durante 1883-1910 cumplió dos fines; en un principio cumplió un fin recaudador hasta 1887 (siendo los derechos de importación el principal componente de ingresos públicos) mediante los aranceles y modificatorias aprobados durante 1883-1886, los cuales obedecieron a la necesidad de recaudar durante la crisis postguerra; y a partir de dicho año se tiende al proteccionismo, pues tuvo como finalidad industrializar ciertos sectores (agrario, minero y manufacturero) destruidos por la guerra, incrementando los aranceles a los bienes finales y reduciendo los de los insumos y bienes de capital.

Sin embargo, a fines del periodo la fluctuación de los precios de exportación había causado inestabilidad en la política arancelaria, no permitiendo alcanzar los objetivos trazados de la política proteccionista.

\section{De 1910 a 1922}

Para comprender aún mejor el contexto económico del periodo de 1910-1922, Carlos Boloña plantea una división en tres sub-periodos: los años previos a la Primera Guerra

11 idem, p. 68 
Mundial (1910-1914), los años de la Primera Guerra Mundial (1914-1918) y los años de la postguerra (1919-1922). ${ }^{12}$

En el sub-periodo previo a la Primera Guerra Mundial, el nivel de apertura de la economía peruana permaneció intacto. Los derechos de importación constituyeron el $42 \%$ del total de los ingresos fiscales. Durante los primeros años de la Primera Guerra Mundial, los ingresos por derechos de importación se redujeron, por lo que en agosto de 1915 se optó por establecer derechos de exportación de tipo específico, pero bajo un régimen variable que los llevó a incrementarse en relación directa con el precio de exportación. Esta reducción en los ingresos por derechos de importación se debió principalmente a las consecuencias económicas de la Primera Guerra Mundial, entre estas, la interrupción del tráfico comercial, disminución de las importaciones, incremento de los fletes internacionales y la expansión del papel del gobierno en la economía.

Por otro lado, las divergencias entre la Superintendencia General de Aduanas y la Junta Aduanera (constituida principalmente por miembros de la Cámara de Comercio de Lima) no permitieron un avance en materia de política arancelaria.

En mayo de 1914, se nombró un comité encargado de elaborar un nuevo arancel con el objetivo de encontrar un rumbo a la política arancelaria, el cual fue aprobado en mayo de 1920 (Ley No 4106).

El nuevo arancel constaba de aproximadamente 1400 partidas, a diferencia del anterior que había constado de más de 3000 partidas, originando esta simplificación inconvenientes en la recaudación y en el nivel de protección.

Debido a estos problemas una parte del grupo industrial ejerció presión al gobierno, logrando en abril de 1921 que se nombre un nuevo comité encargado de la revisión del arancel de 1920 .

Respecto a la participación de los derechos de importación y exportación, durante el periodo de 1915-1922 los derechos de exportación sustituyeron a los derechos de importación como fuente de ingresos ${ }^{13}$, ya que resultaba una forma más fácil y menos costosa de recaudar, en tanto que los esfuerzos recaudadores del gobierno se concentraban en un pequeño grupo de productos de exportación, pero a raíz de los factores externos ocurrió la crisis comercial de 1921 que provocó una caída de los precios de exportación a un 40\% de los niveles de 1920.

12 Ídem, p. 82

13 La participación de los derechos de exportación en los ingresos fiscales alcanzó un 32.6\% debido a que los precios de exportación aumentaron en 297\% para los productos no tradicionales (petróleo y ciertos metales). 
Después de la crisis comercial 1921 originada por la caída de los precios de exportación, el gobierno debía encontrar una fuente de ingresos menos inestable y más segura que los derechos de exportación.

\section{De 1923 a 1935}

Durante 1923 y 1935, se produjo el retorno a la protección, debido a un aumento de aranceles entre 1923-1928 y a la adopción de barreras no arancelarias. En este periodo, se avanzó poco en materia de política arancelaria. Los derechos arancelarios desempeñaron un papel secundario como instrumento de política comercial no solo en el Perú, sino que sucedió lo mismo en muchos países, en los que se adoptó las devaluaciones competitivas ${ }^{14}$ o controles cambiarios como instrumentos para recuperar el mercado mundial o proteger las industrias nacionales.

En el Perú, los derechos arancelarios como instrumento de política comercial fueron relegados a un segundo plano por políticas cambiarias. Los aranceles de 1923 y 1928 fueron los instrumentos principales de la política arancelaria de este periodo, resultando más proteccionistas que el de 1902, pues otorgaron desgravación arancelaria a todos los insumos y materias primas utilizados en los sectores que se buscaba proteger y para los bienes considerados superfluos se establecieron aranceles altos.

Durante 1926 y 1927, se incrementaron los derechos sobre bienes suntuarios en virtud de una "Ley de Emergencia" que concedió facultad al Poder Ejecutivo para tal fin, con lo cual se pretendía mejorar el tipo de cambio y proteger las industrias nacionales. Dichos aumentos se formalizaron con el Arancel de 1928, como mecanismo de recaudación y de protección.

Durante 1927-1928 se vivió un clima de relativa estabilidad económica, habiéndose superado la crisis comercial de 1925; sin embargo, en 1929 la Gran Depresión golpeó tremendamente nuestra economía.

Hacia 1929 los derechos de exportación habían perdido fuerza como fuente de ingresos fiscales, debido a que los precios de exportación continuaron cayendo. Aunada a esta situación, la producción agrícola se vio afectada por las inundaciones en el norte del país, ocasionando reducción en las exportaciones y crisis comercial.

En 1932, el gobierno de Leguía se encontraba económicamente arruinado, por lo que se dio inicio a la recuperación económica del país. En dicho año, ingresaron mercancías con

14 Las devaluaciones competitivas constituyen un instrumento de política económica de carácter proteccionista que consiste en devaluar la propia moneda con el fin de incrementar la demanda internacional de bienes y servicios exportados por un país determinado, al tiempo que se encarecen los bienes y servicios de importación del resto de países del mundo. 
aranceles reducidos como consecuencia de tratados comerciales, con la finalidad de reducir los efectos de la Gran Depresión; no obstante, dichos tratados no lograron la reducción de los efectos negativos.

En cuanto a las barreras no arancelarias adoptadas en el periodo de 1923-1935, sostiene Carlos Boloña que se pueden identificar tres: prohibición de importaciones, monopolios estatales (llamados "Estancos") y monopolios industriales concedidos al sector privado para estimular la industria nacional. ${ }^{15}$

Como vemos, durante 1923-1935 no tuvimos una "política decidida de promoción industrial", lo que tampoco sucedió en ninguno de los periodos con tendencia proteccionista hasta ahora revisados, tendrían que pasar varios años más para que el Estado adopte una política real de impulso a la industrialización.

No obstante, podemos concluir del desarrollo de las políticas arancelarias aplicadas desde 1821-1935 y de las medidas adoptadas al respecto, que el arancel fue un instrumento de recaudación durante los periodos de crisis económica. A partir de la década de 1930, las crisis económicas se han asociado tanto a políticas proteccionistas como a las liberales.

Resulta conveniente mencionar que en este periodo se aprobó, mediante Decreto Supremo del 21 de abril de 1926, el primer cuerpo legislativo en materia aduanera denominado "Código de Procedimientos Aduaneros", el cual tuvo una vigencia de 47 años. ${ }^{16}$

\section{De 1935 a 1948}

Se trata de un periodo en el que las políticas relativamente liberales fueron sustituidas por controles directos. El periodo inició con una política de tendencia liberal, pero durante la década del cuarenta se revirtió por los efectos económicos de la Segunda Guerra Mundial y el conflicto entre Perú y Ecuador sobre reclamos territoriales.

Los controles de precio y tipo de cambio adoptados para combatir la crisis de la balanza de pagos de 1947-1948 reemplazaron al arancel como instrumento de protección. Se hicieron algunos intentos para restablecer el objetivo fiscal del arancel, pero los controles cambiarios, los tratados comerciales y otras reducciones y exoneraciones arancelarias hicieron del arancel un instrumento de importancia secundaria.

Entre las medidas económicas más importantes adoptadas entre 1935 y 1948 estuvieron: la Ley de Promoción Industrial No 9140 de 1940, la creación de entidades públicas, la

15 Ídem, p. 100

16 El Código de Procedimientos Aduaneros fue derogado por la Ley General de Aduanas aprobada por Decreto Ley No 20165 de 02 de octubre de 1973. 
imposición de los controles de precios y subsidios para los alimentos, la devaluación del sol y la consiguiente adopción de medidas de control cambiario.

Con la citada Ley de Promoción Industrial, se buscó promover la industrialización, ya que mediante esta norma el Poder Ejecutivo fue autorizado a celebrar contratos con empresas privadas con la finalidad de proteger y promover la industrialización. Los incentivos otorgados fueron básicamente de tipo fiscal (exoneraciones o reducciones de impuestos y de derechos importación).

A fines de 1939, el Estado buscó intervenir en la economía mediante la creación de empresas públicas. Luego del estallido de la Segunda Guerra Mundial se prohibió la exportación de bienes de primera necesidad y el incremento de sus precios, además que se buscó regular los precios de los productos manufacturados y materiales de construcción, como medidas orientadas a impedir que se repitieran las experiencias funestas de la Primera Guerra Mundial, aunque no fueron suficientes.

Entre 1935-1948, el tipo de cambio atravesó tres fases distintas, puesto que entre 19351938 se decretaron revaluaciones y una devaluación como consecuencia de la recesión de 1937-1938, la cual continuó hasta 1941, año en el que el tipo de cambio se estabilizó. La estabilización del tipo de cambio fue resultado de la adopción de un mecanismo de control en el que intervinieron los principales exportadores y el Estado. Este mecanismo voluntario de control permitió mantener la estabilidad del tipo de cambio hasta fines de 1944 (en que el sol se debilitó) y consistió en que los exportadores vendían al Estado sus ingresos en divisas de acuerdo al tipo oficial y el Estado las distribuía entre los bancos comerciales.

A inicios de 1945, se adoptaron medidas para controlar el tipo de cambio y las importaciones. El mercado cambiario se dividió en oficial y libre; las exportaciones tenían que contar con licencias, que eran otorgadas a quienes se comprometían a vender todos sus ingresos en divisas al Banco Central de Reserva o a los bancos comerciales; se dispuso un tipo de cambio fijo; y se estableció para las importaciones un sistema de licencias para la asignación de divisas negociadas al tipo de cambio oficial, además que obtenida la licencia era necesaria una autorización de importación.

En abril de 1947, el Estado estableció una lista de prioridades en relación a las solicitudes de licencias: Grupo A (alimentos, productos farmacéuticos, bienes de capital y ciertas materias primas), Grupo B (bienes de consumo, insumos y maquinarias), Grupo C (artículos semisuntuarios) y Grupo D (bienes prohibidos como ciertos tipos de vehículos y bienes producidos en el país). 
En 1948, se adoptaron nuevas medidas recomendadas por el Fondo Monetario Internacional que apuntaron a flexibilizar el sistema de control cambiario; sin embargo, no sirvieron de mucho. Durante este periodo tuvimos los Aranceles de 1935 y 1947. El Arancel aprobado en marzo de 1935 se basó en derechos ad valorem y específicos, con orientación a la obtención de los ingresos fiscales, aunque incluyó también algunos derechos proteccionistas ${ }^{17}$; y el Arancel de 1947 básicamente mantuvo las tasas arancelarias impuestas con el Arancel de 1935.

El Perú suscribió tratados comerciales con Francia, Reino Unido, Colombia, Brasil, Estados Unidos y Chile, pero a fines de este periodo la mayoría de los tratados habían llegado a su término sin ser renovados, debido a que el Perú comenzó a adoptar prácticas comerciales multilaterales por recomendaciones del GATT; por lo que, si bien los Tratados Comerciales suscritos en este periodo no fueron muy significativos en índices de importaciones, de cierta manera moderaron las medidas de política arancelaria.

Entre 1945-1948, el arancel volvió a asumir un rol secundario debido a que el sistema de control cambiario lo sustituyó como instrumento de protección y reducción de importaciones, mientras que otros tributos lo reemplazaron como fuente de ingreso fiscal.

Debemos acotar que este periodo fue de naturaleza distinta a las etapas anteriores, en términos de los motivos que impulsaron la adopción de la política arancelaria. La protección adoptó la forma de controles de precio y tipo de cambio, impuestos para enfrentar la crisis de la balanza de pagos de 1947-1948.

Asimismo, como hemos indicado, el arancel se vio restringido como consecuencia de la celebración de un gran número de Tratados Comerciales después de la Gran Depresión y debido al hecho de que su reforma estuvo sujeta a la autorización del Congreso.

\section{De 1949 a 1959}

La política arancelaria asumida durante el periodo de 1949-1959 tuvo por objeto hacer nuevamente del arancel una fuente de ingresos fiscales, aunque en los años de crisis (1952-1953 y 1957-1958) de la balanza de pagos se orientó al proteccionismo mediante el incremento de los derechos arancelarios de ciertos productos y reducción de otros.

En 1949, el Poder Ejecutivo fue autorizado para realizar reformas en relación a los derechos arancelarios según la necesidad de la economía del país, por lo que en ese mismo año se

17 En 1940, los derechos de importación fueron incrementados en 20\% (excepto los alimentos) con la finalidad de aminorar el perjuicio fiscal ocasionado por la Segunda Guerra Mundial. 
eliminaron las prohibiciones de importación dictadas en 1947, incentivando de esta manera la competitividad de algunas industrias. Asimismo, en 1950 se reemplazó todas las sobretasas por un derecho de importación adicional único que varió entre 4-7\% del valor CIF de las mercancías.

Durante la crisis de la balanza de pagos entre 1957 y 1959, se incrementaron los derechos de importación para bienes no esenciales en un 25-100\%; así también se incrementaron los derechos arancelarios a la importación de los sacos de yute como medida de protección, lo que no fue tomado del todo bien, debido a que se trataba de un insumo necesario para el sector agrícola.

En 1951, el Perú ingresó al GATT, implicando ello una limitación de la facultad discrecional del Estado en la aplicación de medidas arancelarias; motivo por el cual, durante la crisis de 1957-1958 el Perú renunció a sus obligaciones a fin de poder imponer sobretasas de importación hasta 1961.

En esta década, se adoptaron una serie de medidas para que el sector de las exportaciones tradicionales recuperara su lugar como fuente principal de ingreso fiscal. Para Carlos Boloña, algunas de las medidas económicas más importantes fueron: la promoción de las exportaciones tradicionales, supresión de un gran número de subsidios y mecanismos de control de precios, desactivación de mecanismos de control cambiario y el restablecimiento del objetivo fiscal del arancel de importación, muchas de las cuales se adoptaron por recomendación de la Misión Klein, que asesoró al gobierno de Odría entre 1949 y $1955 .{ }^{18}$

En cuanto a las medidas adoptadas con respecto al tipo de cambio, se implantó en diciembre de 1948 un nuevo sistema cambiario basado en un mercado oficial y uno de certificados que consistía en que los exportadores debían comprar certificados en moneda extranjera en el Banco Central por un valor equivalente a $55 \%$ del producto desus exportaciones a un tipo de cambio oficial. En 1949 fue reformulado, estableciéndose que los exportadores debían entregar sus ingresos endivisas y recibían certificados en moneda extranjera, los cuales eran de libre negociación y tenían una vigencia determinada, luego de la cual eran compradas por el Banco Central de Reserva al tipo de cambio vigente para los certificados menos el $2 \%$. Posteriormente, se optó por el establecimiento de un sistema de tipo de cambio fijo hasta que en 1959 se aprobó un nuevo programa de estabilización que incluyó entre las medidas a aplicar: la eliminación de subsidios, eliminación de restricciones comerciales y sustitución del sistema de certificados en moneda extranjera por un sistema cambiario libre.

18 Ídem, p. 122 
Como vemos, en la década 1949-1959 se buscó restaurar el objetivo fiscal del arancel; no obstante, debido a las crisis económicas de 1952-1953 y 1957-1958 nuevamente el Estado comenzó a sentirse atraído por el proteccionismo, por lo que ya en la década del cincuenta se había comenzado a forjar la política proteccionista de la década del sesenta, mediante reducciones y exoneraciones arancelarias a bienes de capital y equipos para las industrias extractivas e insumos para la industria textil.

\section{De 1960 a 1968}

El periodo 1960-1968 se caracterizó por adoptar una política arancelaria orientada a la industrialización. A inicios de este periodo, gozábamos de un clima económico favorable, el cual llegó a su fin durante la crisis de la balanza de pagos de 1967-1968.

Durante 1960-1964, tuvimos un auge en las exportaciones, principalmente de harina de pescado y minerales, siendo un periodo breve de economía abierta. Se aprobó la Ley de Promoción Industrial No 13270 de 1959, que tuvo como objetivo promover el sector manufacturero mediante exoneraciones y reducciones arancelarias para este sector, quizá a expensas de los demás sectores (se incrementaron las tasas arancelarias para los bienes de consumo duradero).

Durante 1959 y 1963, se elevó el nivel de protección al incrementarse los derechos arancelarios en varias oportunidades; disponiéndose en diciembre de 1962 un arancel ad valorem adicional de 150\% sobre varios productos de acero. Se expidieron dos Aranceles proteccionistas más efectivos que los de 1890-1910 y 1923-1928, resultado de una verdadera política de promoción industrial asumida, según sostienen Aliaga y Chirinos. ${ }^{19}$

El Arancel de 1964 permitió consolidar la tendencia proteccionista y promovió el sector manufacturero. Se trató de un Arancel sin crisis aprobado en una etapa de prosperidad económica (pleno auge de las exportaciones), a diferencia de los Aranceles hasta ese momento aplicados en el Perú, los cuales habían sido expedidos en periodos de crisis económicas.

Para Carlos Boloña, el arancel de 1964 tuvo como principal objetivo promover la industrialización por sustitución de importaciones a cualquier costo. ${ }^{20}$

La crisis que atravesó la balanza de pagos en 1967 motivó a que se expidieran los Decretos Supremos $\mathrm{N}^{\circ} 137-\mathrm{H}$ y $\mathrm{N}^{\circ}$ 202-68-HCorientados a incrementar los ingresos fiscales.

\footnotetext{
ALIAGA Y CHIRINOS, op. cit. p. 36

BOLOÑA, op. cit. p. 134
} 
Mediante el Decreto Supremo $\mathrm{N}^{\circ} 137-\mathrm{H}$ de 05 de junio de 1967, se puso en vigencia el Arancel de 1967, basado en el de 1964 pero orientado a restringir aún más el nivel de importaciones, sobre todo para los bienes de consumo duraderos; asimismo, con el Decreto Supremo $\mathrm{N}^{\circ}$ 202-68-HC se estableció una sobretasa temporal de $10 \%$ sobre el pago de importaciones, entre otras medidas (se prohibió la importación de artículos suntuarios y se suspendieron algunas exoneraciones arancelarias); sin embargo, estas disposiciones únicamente lograron reducir los ingresos fiscales.

En 1968, se establecieron además como barreras no arancelarias, la prohibición temporal de las importaciones de artículos no esenciales mediante Decreto Supremo No 053-68-HC, y un impuesto de $15 \%$ sobre las adquisiciones de certificados de divisas para el pago de importaciones y las deudas por importaciones mediante Decreto Supremo No 173-68-HC.

El arancel fue utilizado en esta etapa como el principal instrumento de protección, la exoneración total o parcial de los aranceles sobre las importaciones de bienes intermedios o de capital ocuparon un segundo lugar como instrumento de protección.

El objetivo principal del arancel fue la industrialización, ya que se buscó proteger al sector manufacturero, desempeñando los grupos de presión un rol importante en el otorgamiento de protección por parte del Estado.

La protección aumentó debido a la política sustitutiva de importaciones asumida, alcanzando niveles sin precedentes. La política de sustitución de importaciones generó el estancamiento de la producción y las exportaciones, siendo una de las causas del colapso de la economía peruana a fines de la década del ochenta como veremos en los siguientes periodos analizados.

Paz Soldán y Rivera, al respecto, sostienen que las políticas de sustitución de importaciones aplicadas en los países en desarrollo como el Perú significaron el establecimiento de medidas arancelarias y para-arancelarias orientadas a limitar las importaciones y el comercio exterior. Las primeras consistieron en impuestos que afectaban únicamente a los productos importados; por lo general, se aplicaba menores aranceles a la importación de insumos y bienes de capital requeridos por las industrias que se deseaba proteger, elevándose el nivel de protecciones efectivas de estas últimas.

Las medidas para-arancelarias establecían restricciones a las importaciones a través de permisos, licencias, cuotas de importación y prohibiciones para importar determinadas categorías de productos, entre otras restricciones al libre comercio. Adicionalmente, se 
aplicaban tipos de cambio diferenciados para favorecer el ingreso de ciertos productos y se otorgaba subsidios a los sectores protegidos. ${ }^{21}$

De acuerdo con la teoría de sustitución de importaciones, la política comercial debía proteger temporalmente a las industrias o sectores nacientes, que al principio no contarían con ventajas competitivas, pero que gracias a la protección del Estado se fortalecerían gradualmente hasta poder competir en el mercado extranjero.

\section{De 1969 a 1975}

Las medidas proteccionistas en este periodo fueron principalmente no arancelarias, las mismas que inicialmente fueron impuestas como temporales, convirtiéndose posteriormente en permanentes.

Para Boloña, fue un periodo altamente proteccionista, en el que se continuó el proceso de sustitución de importaciones pero bajo diferentes condiciones, en tanto que el Perú se había embarcado en un programa de "reformas estructurales a cualquier costo" que ocasionó un mayor control de la economía por parte del Estado, una economía más cerrada y mayores niveles de protección, debido a la imposición de barreras no arancelarias, monopolios estatales y controles de cambio. ${ }^{22}$

Se aplicó un modelo de promoción de exportaciones (Certex) para productos no tradicionales, lo cual implicó rebaja de derechos e impuestos y la exoneración de otros en montos variables de acuerdo a ciertos criterios. ${ }^{23}$

Mediante Decreto Ley Nº 19852 de 26 de diciembre de 1972, se aprobó un nuevo Arancel de Aduanas basado en la NABANDINA. Al respecto, Aliaga y Chirinos sostienen que el objeto de la aprobación del Arancel de 1972 fue el de consolidar los derechos ad valorem adicionales fijados desde 1968 y crear un esquema de reducción arancelaria por cada sector económico, bajo el principio de "hecho a la medida" que dominó la política arancelaria. ${ }^{24}$

El Banco Central de Reservas fue el encargado de administrar la asignación de divisas en

21 PAZ SOLDÁN, Julio y RIVERA, María del Carmen. "La Reforma Comercial y de Aduanas". En: ABUSADA, Roberto y otros (editores). La Reforma Incompleta rescatando los noventa. Lima: Centro de Investigación de la Universidad del Pacífico, $1^{\text {a }}$ edición, 2000, p. 258

22 BOLOÑA, op. cit. 155

23 El Certificado de Reintegro Tributario a las Exportaciones (CERTEX) permitía el reintegro del valor de las mercancías no tradicionales exportadas. El porcentaje se calculaba sobre el valor FOB, y CIF en el caso que la mercancía haya sido exportada por embarcaciones peruanas. El certificado era transferible y con poder cancelatorio para el pago de gravámenes de importación, de exportación y el pago del impuesto sobre bienes y servicios.

24 ALIAGA Y CHIRINOS, op. cit. p. 37 
el mercado de certificados ${ }^{25}$ y la recepción de las solicitudes de licencias para la utilización de divisas era responsabilidad de juntas especiales que representaban tanto al sector privado (Jutrex) como al sector público (Cotrex), concediendo además las licencias.

Este sistema de control cambiario funcionó bien desde 1971 hasta mediados de 1974, debido a la entrada creciente de divisas como consecuencia de los elevados precios de exportación y el ingreso de varios préstamos del exterior destinados a financiar proyectos del gobierno. Sin embargo, a mediados de 1974 la balanza de pagos entró en crisis debido a la caída de los precios de exportación, a la recesión experimentada por el mundo occidental durante 19741975, y al nivel elevado de importaciones durante dicho periodo. Las citadas juntas especiales redujeron la cantidad de licencias otorgadas ${ }^{26}$, pero el Perú ya sufría nuevamente una crisis económica a mediados de 1975.

Se aprobó la Ley General de Industrias - Ley No 18350 de 27 de julio de 1970 buscando promover la industrialización. Mediante esta Ley se establecieron cuatro niveles de prioridad en el sector industrial. En el primer nivel, estuvieron las industrias básicas (productoras de insumos esenciales, de bienes de capital y de tecnología industrial); en el segundo nivel, se incluyeron las industrias de bienes esenciales (alimentos y ropa por ejemplo) e insumos para los sectores productivos; en el tercer nivel, estuvieron incluidas las industrias de bienes no esenciales y el cuarto nivel correspondía a los artículos suntuarios. El Ministerio de Industria fue el encargado de asignar los niveles de prioridad y de acuerdo al nivel se concedían reducciones en los aranceles sobre los insumos y bienes de capital.

Asimismo, mediante la norma en mención se estableció un Registro Nacional de Manufacturas (RNM), prohibiéndose la importación de productos fabricados localmente que estuvieran inscritos en tal Registro. Todos los sectores económicos tuvieron su propio esquema de reducciones arancelarias para insumos y bienes de capital utilizados en su sector, debido a una serie de reducciones y exoneraciones decretadas. Los derechos dejados de percibir en 1975 representaron el 50\% de los derechos de importación recaudados.

Durante 1971-1976, el gobierno tuvo el derecho exclusivo de importar productos básicos (petróleo crudo y alimentos) e insumos básicos para el sector industrial (fertilizantes, cemento, parafina, etc.), constituyendo las importaciones del Estado aproximadamente un 30\% del total de importaciones.

25 El sistema de Certificado de Divisas consistió en el cambio del recibo de moneda extranjera por un certificado de dicha moneda emitido por el Banco Central de Reserva del Perú, que podía ser utilizado para el pago de los derechos de las importaciones de acuerdo a la cuota asignada a cada importador.

26 Para 1974 se había duplicado el volumen de importaciones. 
Parte de los bienes importados por el gobierno eran vendidos al sector privado al precio de mercado más una comisión o a precios subsidiados en el caso de alimentos o combustible, convirtiéndose el Estado en el mayor intermediario comercial.

Durante 1969-1975, tuvimos nuevamente una política altamente proteccionista; siendo los instrumentos principales de política arancelaria, la Ley General de Industrias - Ley No 18350, el Arancel de 1973 y las restricciones no arancelarias dispuestas durante el periodo.

El objetivo del gobierno militar era reducir la dependencia de la economía peruana del exterior y desarrollar una industria local orientada hacia el mercado interno que no dependiera de las importaciones ni del capital extranjero. Con dicho fin, se elevaron los aranceles y se establecieron diversas medidas para-arancelarias, como licencias previas para importación y prohibiciones a las importaciones; asimismo, para crear una industria intensiva en capital, se crearon diversas empresas estatales en las actividades en las que se consideraba no existía suficiente capital privado nacional, según sostienen Paz Soldán y Rivera. ${ }^{27}$

\section{De 1975 a 1979}

Carlos Boloña denomina este periodo "de la incertidumbre a la liberalización", y señala al respecto que luego de un periodo inicial de "retórica reformista" y en medio de una de las mayores crisis del siglo XX, el gobierno militar optó por una política más liberal orientada al capital y al comercio exterior como resultado de la aplicación de varios paquetes de estabilización del Fondo Monetario Internacional. ${ }^{28}$

Durante 1976-1978, continuaron las restricciones de importaciones mediante barreras no arancelarias. En enero 1976, se dispuso que todas las mercancías importadas debieran contar con licencias previas del Ministerio de Comercio, entrando en vigencia esta disposición en 1977. Posteriormente, las prohibiciones y restricciones de mercancías a importar fueron sustituidas por una relación de importaciones permitidas que constaba únicamente de 276 partidas; aunque, a la relación de partidas permitidas también se les aplicó el sistema de licencias previas.

El énfasis en la promoción de exportaciones no tradicionales llegó a su clímax en noviembre de 1978, con la promulgación de la "Ley de Promoción de Exportaciones No Tradicionales", mediante la cual se reiteró la vigencia del Certex y otorgó otros mecanismos tributarios y financieros a favor de ese sector como, por ejemplo, la admisión temporal para las materias primas e insumos intermedios importados,suspensión temporal de aranceles a la importación de bienes de capitaly créditos tributarios por reinversión, entre otros.

27 PAZ SOLDÁN y RIVERA, op. cit. p. 259

28 BOLOÑA, op. cit. p. 155 
En 1979, se comenzó a flexibilizar el sistema rígido de importaciones, con el reemplazo del Registro Nacional de Manufacturas (RNM) por una lista de importaciones prohibidas aplicable hasta el 31 de diciembre de 1980; sin embargo, antes de esa fecha (en diciembre de1979) se eliminó la lista de importaciones prohibidas, incorporándolas en las lista de importaciones permitidas. En 1980 año se levantaron las restricciones cuantitativas de 1000 partidas aproximadamente.

Aliaga y Chirinos al respecto sostienen que en cumplimiento de la reforma arancelaria contemplada en el Programa Económico de 1978-1980, se inició el programa de adecuación progresiva hacia un arancel definitivo y único. Se actualizaron, consolidaron y reordenaron los derechos e impuestos a las importaciones debido a que se tenía una multiplicidad y superposición de regímenes exoneratorios que dificultaban la utilización del arancel como instrumento eficaz de política económica. ${ }^{29}$

Según lo señalado, debemos indicar que en este periodo corto se adoptó una postura de liberalización de la política arancelaria que contradice el concepto de "arancel de crisis", porque se adoptó una política liberal en plena crisis económica.

\section{De 1980 a 1990}

A inicios de la década de los ochenta, se intentó reducir el nivel de protección de la industria; sin embargo, debido a la crisis económica de 1982 concluyó el intento de reforma, dictándose nuevamente prohibiciones y restricciones al comercio exterior en 1983. Entre las modificaciones dispuestas en relación a las tasas arancelarias, en setiembre de 1980, se pasó de un nivel arancelario máximo de $155 \%$ a $60 \%$ y en 1981 se redujeron en promedio entre $5 \%$ y $7 \%$ los niveles arancelarios de losvegetales, grasas y aceites, insumos utilizados en la fabricación de papel, manufacturas de piedra, yeso y cemento, así como también de material de transporte.

De la misma manera, se efectuaron cambios en cuanto a las barreras no arancelarias, ya que en diciembre de 1981 el 98\% de subpartidas arancelarias eran de libre importación y solo 112 partidas tenían la condición de restringidas, las cuales básicamente eran productos agropecuarios, derivados del petróleo, papel, fertilizantes y naves.

En enero de 1982, se comenzaron a tomar medidas para incrementar la recaudación fiscal, imponiéndose una sobretasa arancelaria de $15 \%$ aplicable a todas los niveles arancelarios, la cual en 1983 pasó a ser aplicable solo a las mercancías gravadas con un arancel ad valorem

29 ALIAGA Y CHIRINOS, op. cit. p. 38 
mayor a cero; no obstante, el relativo orden de estos años de etapa liberal comenzó a alterarse mediante modificaciones a los derechos ad valorem con aires proteccionistas.

En 1985, se estableció una política económica que buscó reactivar la economía en base a medidas proteccionistas que favorecieran la industria local. Se establecieron mayores aranceles, licencias previas, registro de importadores, un sinnúmero de restricciones fitosanitarias y zoosanitarias, control de tipo de cambio, cuotas de importación y prohibición a la importación de ciertos productos.

Respecto de las medidas para-arancelarias se debe indicar que, a partir de diciembre de 1987 hasta agosto de 1988, las subpartidas que aún se mantenían libres se añadieron a aquéllas previstas como restringidas, por lo que, en otras palabras, el 100\% del universo arancelario estaba bajo algún tipo de restricción, según lo señalado por Boloña e Illescas. ${ }^{30}$

El arancel no adoptó un papel importante en la reactivación industrial, los otros mecanismos de protección afectaron su desarrollo. La política arancelaria asumida fue de marcada orientación proteccionista, sobre todo durante 1985-1990, poniéndose énfasis además en políticas de impulso al crecimiento del mercado interno.

\section{De 1990 a 2001}

A partir de la década de los noventa, el ambiente económico internacional favoreció las políticas comerciales con tendencia a incrementar el libre comercio. Los países latinoamericanos adoptaron políticas comerciales con miras a una reducción de aranceles y eliminación de las trabas a las importaciones y exportaciones, tal como sostiene Aguilar Puntriano. ${ }^{31}$

El Perú no pudo ser ajeno a esta tendencia y la política arancelaria comenzó su desarrolló en el marco de un proceso de apertura de la economía hacia el comercio exterior.

El sistema proteccionista con múltiples niveles arancelarios e innumerables barreras paraarancelarias fue sustituido.

A inicios de los noventa, el arancel tenía una estructura de 39 niveles arancelarios, siendo modificado con el Decreto Supremo No 228-90-EF que redujo los niveles a 23, pasando el nivel mínimo de $15 \%$ a $10 \%$ y el máximo de $84 \%$ a $50 \%$. Sin embargo, es en setiembre de

30 BOLOÑA BEHR, Carlos e ILLESCAS MUCHA, Javier. Políticas Arancelarias en el Perú 1980-1997. Lima: Instituto de Economía de Libre Mercado, 1997, p. 49.

31 AGUILAR PUNTRIANO, Alejandro Raúl. "Una visión sobre la evolución de la política arancelaria del Perú y su repercusión dentro del comercio intrarregional entre los países miembros de la CAN", p. 4. Consulta: 24 de mayo de 2011.http://www.eclac.org/ilpes/noticias/paginas/3/19803/AAGUILAR.doc 
1990 que se realiza la primera gran modificación arancelaria mediante Decreto Supremo No 257-90-EF que redujo los niveles arancelarios a tres: 15\%, 25\% y 50\%, manteniéndose una sobretasa del $10 \%{ }^{32}$ para los bienes gravados con tasas de $25 \%$ y 50\%; asimismo, mediante dicho Decreto Supremo se eliminaron la mayor parte de las prohibiciones y demás restricciones a la importación.

El año siguiente, mediante Decreto Supremo No 033-91-EF de 12 de marzo de 1991 los niveles arancelarios se redujeron a dos: 15\% para el 98\% de subpartidas aproximadamente y $25 \%$ para el resto de mercancías del arancel (comprendían principalmente productos textiles, calzado, productos agrícolas y electrodomésticos). Adicionalmente, dejaron sin efecto las inafectaciones y exoneraciones vigentes con algunas excepciones. ${ }^{33}$

En cuanto a las barreras para-arancelarias, mediantes Decreto Supremo No 060-91-EF de 23 de marzo de 1991, se dispuso la eliminación de todo tipo de restricciones administrativas al flujo de comercio exterior. Se dejaron sin efecto las licencias, visaciones previas y consulares, cuotas, registros de importadores o exportadores, permisos y otras restricciones de cualquier naturaleza que afecten la importación y exportación de bienes, con las excepciones establecidas en el Texto Único de Productos de Exportación Prohibida, restricciones derivadas de normas cambiarias y las establecidas por razones sanitarias, defensa del patrimonio cultural, medio ambiente, orden interno y seguridad del país.

El 14 de setiembre de 1991 fue publicado el Decreto Legislativo No 668, Ley Marco del Comercio Exterior Peruano, mediante el cual se establecieron principalmente las siguientes directrices: libertad de comercio exterior, libre disposición y convertibilidad de moneda extranjera (tipo de cambio único), libertad de prestación de servicios por operadores privados, eliminación del monopolio estatal en producción y comercialización, eliminación de exoneraciones y rebajas arancelarias a ciertos sectores, eliminación de subsidios, principio de presunción de veracidad en los trámites y control del comercio desleal.

Estas modificaciones dentro del marco del proceso de liberalización del comercio exterior retardaron la adecuación del Arancel nacional a la Nandina, la cual al final se cumplió con el Decreto Supremo Nº63-92-EF que aprobó el Arancel de Aduanas basado en la Nomenclatura Arancelaria Común de los Países Miembros del Acuerdo de Cartagena-Nandina, la misma que se sustenta en el Sistema Armonizado de Codificación y Designación de Mercancías.

32 Se dispuso que la sobretasa estaría vigente hasta el 31 de diciembre de 1990, sin embargo en noviembre de dicho año fue dejada sin efecto mediante el Decreto Supremo N²94-90-EF.

33 Excepto las importaciones que realicen las universidades y centros educativos; agentes diplomáticos; donaciones a instituciones benéficas; importaciones de oro, plata, entre otros; equipaje y menaje; e importaciones de equipo y armamento destinado a la defensa nacional y orden interno. 
Mediante Decreto Supremo No 035-97-EF de 13 de abril de 1997, fueron reducidas las tasas arancelarias a un $12 \%$ ad valorem para el $85 \%$ del universo arancelario y el $15 \%$ restante fue gravado con una tasa de $20 \% .{ }^{34}$ Adicionalmente, se dispuso una sobretasa temporal de 5 $\%$ para algunas subpartidas como malta y extracto de malta, maíz amarillo, azúcar y algunas clases de licores. En ese sentido, en la práctica el arancel efectivo tenía tasas de 25\%, 20\%, $17 \%$ y $12 \%$ al no aplicársele a todas las subpartidas la sobretasa de 5\%.

La política arancelaria cambió de una política arancelaria que se caracterizaba por la imposición de altos niveles arancelarios, de cuotas y otros tipos de barreras no arancelarias (política de sustitución de importaciones) a una política de total apertura comercial que consistió básicamente en la reducción de las tasas arancelarias y eliminación de barreras al comercio exterior.

El proceso de apertura comercial iniciado no tenía antecedentes en la política comercial del Perú. Consistió básicamente por un lado en la liberalización unilateral que redujo el número de tasas arancelarias y por el otro, en el fomento del comercio preferencial.

Cabe agregar que el proceso de reformas incluyó un programa cambios sustanciales de la Superintendencia Nacional de Aduanas - Sunad, con el fin convertirla en una institución más eficiente y moderna; asimismo, la delegación de funciones al sector privado (agencias de aduana, almacenes aduaneros y bancos) y modificaciones a la legislación aduanera permitieron una reducción de costos en los servicios vinculados al comercio exterior. La política arancelaria se constituyó en un instrumento determinante en el crecimiento económico de los años siguientes, habiéndose eliminado las prohibiciones y restricciones a la importación.

Según Paz Soldán y Rivera, la reforma comercial emprendida se sustentó en que la política de comercio exterior más apropiada para una economía pequeña como la peruana es el libre comercio, ya que permite que el país asigne sus recursos productivos, tanto capital como mano de obra, a las actividades en las cuales goza de ventajas. El libre comercio permite que el país se beneficie del intercambio comercial con otras economías con distinta dotación de factores. ${ }^{35}$

\section{Del 2001 hasta la actualidad}

Este periodo ha significado cambios sumamente importantes en materia arancelaria, con reducciones en los niveles arancelarios, celebración de acuerdos o tratados bilaterales de

34 La tasa de 20\% fue aplicada a las partidas arancelarias del Anexo del Decreto Supremo No 100-93-EF, que dispuso una tasa de $15 \%$ ad valorem a una serie de productos para combatir el contrabando.

35 PAZ SOLDÁN Y RIVERA, op. cit. p. 268 
libre comercio y modificaciones importantes en la legislación aduanera. A partir del 2001, se han venido modificando los niveles arancelarios con tendencia a la apertura comercial. Los cambios se iniciaron con el Decreto Supremo No 073-2001-EF de 26 de abril de 2001, mediante el cual se redujeron las tasas arancelarias a 4\% para una lista de 1390 subpartidas de insumos, partes y piezas.

Continuaron las reducciones de las tasas arancelarias incorporando subpartidas a la lista del Decreto Supremo No 073-2001-EF y excluyendo otras. Así, también, se redujeron las tasas de bienes de capital e insumos, maquinarias y equipos, gas licuado de petróleo, combustibles, entre otros bienes (algunas subpartidas de trigo, maíz amarillo duro, harina de trigo, algunos productos de los reinos animal y vegetal, ciertos productos de las industrias alimentarias, tejidos, etc.); y fue derogándose el derecho ad valorem adicional respecto de ciertas subpartidas.

En el presente año, se han aprobado dos modificaciones de los niveles arancelarios. Con el Decreto Supremo Nº07-2011-EF de 15 de enero de 2011 se fijó tasa de $0 \%$ para 2 subpartidas (cemento sin pulverizar y los demás) y a través del Decreto Supremo No 055-2011-EF de 10 de abril de 2011 se redujo a $0 \%$ la tasa arancelaria para 7 subpartidas (maíz amarillo, blanco y morado, demás maíces para siembra y demás sorgo de grano), disponiéndose además una tasa de $11 \%$ aplicable a 792 subpartidas (carnes, hortalizas, algunas frutas, tejidos, prendas de vestir, calzados, ciertas máquinas, entre otros).

Con todas las modificaciones de los niveles arancelarios dictadas en los últimos años, quedó la siguiente estructura arancelaria: $11 \%$ ad valorem para 792 subpartidas, $6 \%$ ad valorem para 2482 subpartidas, $4 \%$ para 1 subpartida (correspondiente a envíos de entrega rápida) y $0 \%$ para 4104 subpartidas.

Mención aparte merece el documento denominado "Lineamientos de Política Arancelaria" aprobado por Resolución Ministerial No 005-2006-EF/15, mediante el cual se difunde el diseño de política arancelaria del Ministerio de Economía y Finanzas, tanto desde el punto de vista de liberalización unilateral como dentro del marco de las negociaciones comerciales.

Como bien se señala en el citado documento, si bien existe un sesgo "protector" que puede dársele al arancel, éste también suele tener fines recaudatorios del tesoro o de estimulación del empleo, y en ese sentido, cuál sea el uso que se opte por dar al arancel, es una decisión política que debe considerar varios elementos (producción, empleo, recaudación, bienestar de la población, entre otros) y las posibles repercusiones de la política arancelaria adoptada.

Cabe agregar que un país puede impulsar el libre comercio a través de dos caminos; puede optar por una liberalización del comercio de manera unilateral con el objetivo de incrementar 
el comercio con el resto del mundo, y tiene también como opción el comercio preferencial con la finalidad de que dos o más países acuerden mutuas reducciones (preferencias) en las tasas arancelarias de una parte o del total del universo arancelario.

En el Perú, la liberalización del comercio exterior se ha desarrollado en las dos vías, pues como ya se ha indicado, a partir del año 2001 se han venido reduciendo las tasas arancelarias considerablemente (liberalización unilateral) y así también el Perú ha suscrito acuerdos o tratados bilaterales y se encuentra negociando algunos más (fomento del comercio preferencial).

La política de libre comercio adoptada en la década de los noventa ha sido continuada en la última década; sin embargo, aún debemos preocuparnos en continuar perfilando estratégicamente esta política para lograr el desarrollo armonioso del país, pues si bien el Perú cambió la política de sustitución de importaciones o proteccionista por una política de libre comercio a partir de la década de los noventa hasta la fecha no se ha adoptado una estrategia constante de crecimiento orientada hacia el exterior.

Consideramos que resulta necesario para el crecimiento de las exportaciones, y por ende de la economía, la concentración en los productos no tradicionales, exportar bienes con mayor valor agregado y sobre todo diseñar una estrategia exportadora que lleve a un crecimiento sostenido de la economía.

Coincidimos con Mercedes Araoz, quien citando a Rodrick, sostiene que el objetivo principal de los hacedores de la política debe ser el desarrollo económico de las naciones y que la integración al mundo debe ser una de las herramientas para el logro de este objetivo, y no ser el objetivo per se; por lo que se debe tener una estrategia negociadora que sirva para el logro del bienestar de nuestra población. ${ }^{36}$

De manera resumida, se ha presentado la evolución cronológica del arancel y las políticas arancelarias adoptadas en el Perú desde la época colonial hasta nuestros días. Hemos tomado como motivo la necesidad de conocer el papel fundamental del arancel en el desarrollo de las políticas arancelarias del Perú a lo largo de su historia, con el objetivo de que cada uno seamos capaces de diferenciar las implicancias, ventajas y desventajas que pudiera traer consigo la adopción de determinada política arancelaria.

36 ARAOZ, Mercedes. "Perspectivas de la Política Arancelaria y de Integración”. En: Economía y Sociedad 48, CIES abril 2003, p. 40. Consulta: 01 de junio de 2011. http://www.gestiopolis.com/canales5/eco/consorcio/eys48/archivos/48politicas-arancelarias-de-integracion.pdf 


\section{Conclusiones}

Los derechos arancelarios han constituido un instrumento de política comercial a lo largo de nuestra historia. Han sido utilizados durante periodos de crisis económica para aumentar los ingresos fiscales y en otros periodos para impulsar la industria nacional; aunque, como se ha visto, no ha existido una actuación estándar pues ante contextos o situaciones similares, la política arancelaria adoptada en cada uno de los periodos ha tenido características propias muchas veces influenciadas por las corrientes liberales o proteccionistas del exterior.

Los aranceles han sido utilizados durante la evolución de las políticas arancelarias en la protección de la industria nacional, pues los aranceles altos desalientan las importaciones promoviendo la producción nacional, la cual sería requerida para cubrir la demanda interna insatisfecha. Hoy, los aranceles también tienen otras motivaciones que están fundamentadas en objetivos sociales, económicos, salud pública, etc.

Los derechos arancelarios constituyen un factor estratégico en la política arancelaria que se asuma, pues van a permitir regular los intercambios de mercancías extranjeras con la finalidad de proteger la producción interna y de manera secundaria significan un ingreso importante para el Estado mediante la recaudación.

Las funciones fiscalista y proteccionista de los derechos arancelarios no son excluyentes dentro de una política arancelaria, definiéndose ésta según cuál predomine, esto es: política liberal o proteccionista.

\section{Bibliografía}

- ABUSADA, Roberto, DU BOIS Fritz, MORÓN, Eduardo, VALDERRAMA José (editores). La reforma incompleta: rescatando los noventa. Lima: Centro de Investigación de la Universidad del Pacífico, $1^{\text {a }}$ edición, 2000.

- ABUSADA, Roberto, ILLESCAS, Javier y TABOADA, Sara. Integrando el Perú al Mundo. Lima: Centro de Investigación de la Universidad del Pacífico, $1^{\text {a }}$ edición, 2001.

- ADRIAZOLA ZEVALlOS, Juan Carlos. Derecho Aduanero Tributario. Lima: CIFAduanas, $1^{\text {a }}$ Edición, 1999.

- ALIAGA, Juanita y Celinda CHIRINOS. El Arancel de Aduanas. Trabajo de Investigación para optar el Titulo de Oficial de Aduanas, Lima: Escuela Nacional de Aduanas-III Curso de Oficiales de Aduanas, 1996. 
- BOLOÑA BEHR, Carlos. Politicas Arancelarias en el Perú 1880-1980. Lima: Instituto de Economía de Libre Mercado, 1994.

- BOLONAA BEHR, Carlos e Javier ILLESCAS MUCHA. Políticas Arancelarias en el Perú 1980-1997. Lima: Instituto de Economía de Libre Mercado, 1997.

- MARTEL SÁNCHEZ, José Antonio. Estudio Analítico de la Nomenclatura del Sistema Armonizado de Designación y Codificación de Mercancias: Origen, Implementación y Estructura. Lima: Escuela Nacional de Aduanas, Dirección de Investigación y Becas, 1993. 